\title{
Keys for Designing Hematite/Plasmonic Metal Hybrid Nanostructures with Enhanced Photoactive Properties
}

\author{
Ezequiel R. Encina*(-) and Eduardo A. Coronado*(-) \\ Departamento de Fisicoquímica, Facultad de Ciencias Químicas, INFIQC-UNC-CONICET, Córdoba 5000, Argentina
}

Supporting Information

ABSTRACT: Photoactive hybrid nanostructures composed of metal oxides and plasmonic metals are able to perform the conversion of radiant (solar) energy into electrical or chemical energy. However, their use in large-scale practical applications still requires their photoconversion efficiency to be improved. In this work, the light-harvesting properties of hematite/ plasmonic metal rodlike hybrid nanostructures are investigated on the basis of discrete dipole approximation simulations. The effects of the length and nature of the metallic counterpart on the far- and near-field optical properties of the hybrid nanostructure are analyzed in detail. The implemented methodology allowed us to assess the contribution of each
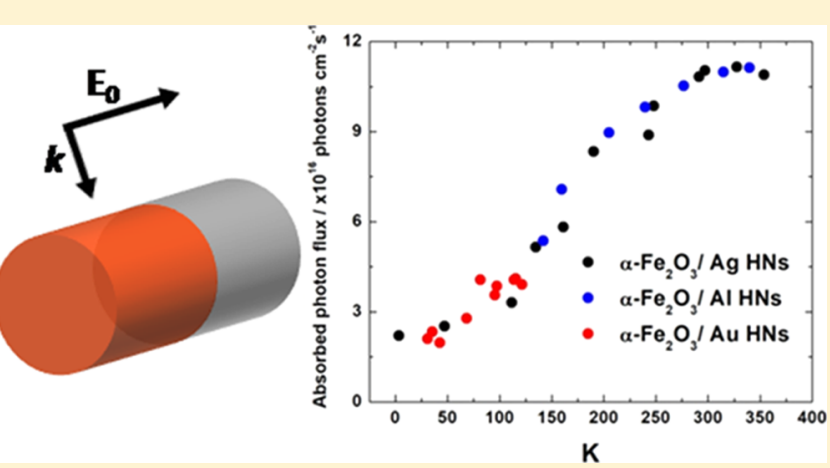
component of the hybrid nanostructure to the absorption efficiency, $Q_{\mathrm{abs}}$, separately. In turn, the $Q_{\mathrm{abs}}$ values obtained were employed to determine the absorbed photon flux, $\phi$, within the $\alpha-\mathrm{Fe}_{2} \mathrm{O}_{3}$ component, a relevant quantity directly related to the photoconversion efficiency. It was found that both absorption efficiency $Q_{\text {abs }}$ and absorbed photon flux $\phi$ can be largely enhanced through a proper selection of the length and nature of the metallic counterpart of the nanostructure, evidencing plasmon-enhanced light absorption in the $\alpha$ - $\mathrm{Fe}_{2} \mathrm{O}_{3}$ component, which is attributed to a plasmon-induced energy transfer mechanism based on near-field enhancements. Importantly, it was found that the highest $\phi$ values achieved for nanostructures composed of $\mathrm{Ag}$ and $\mathrm{Al}\left(\sim 11 \times 10^{16}\right.$ photons $\left.\mathrm{cm}^{-2} \mathrm{~s}^{-1}\right)$ are nearly 3 times larger than those corresponding to nanostructures composed of $\mathrm{Au}\left(\sim 4 \times 10^{16}\right.$ photons $\left.\mathrm{cm}^{-2} \mathrm{~s}^{-1}\right)$. In addition, a direct relationship between the absorbed photon flux, $\phi$, and optical characteristics of the nanostructures, that is, the bandgap energy of $\alpha$-Fe $\mathrm{O}_{3}$ and the energy and radiative line width of the localized surface plasmon resonance, was empirically obtained. Such a relationship not only complements but also overcomes the limitations of the reported useful criteria and provides helpful guidelines for the optimum design of hybrid nanostructures with enhanced photoactive properties.

\section{INTRODUCTION}

The population and industrial growth of our modern society entails a growing energy demand, which is mainly satisfied through the use of fossil fuels. However, the limited amount of these and the negative environmental impact associated with their use make it necessary to develop technologies that allow the use of other sources of energy in a more sustainable way. Solar energy is safe, abundant, and easily accessible and its supply is unlimited. Therefore, radiant energy from the sun constitutes one of the most promising sources to meet the future energy demand. ${ }^{1-5}$ Likewise, to be used in our benefit, solar energy must be converted efficiently into electrical and/or chemical energy by means of photovoltaic and photocatalytic processes, respectively. ${ }^{6-9}$ The metal oxides such as $\mathrm{TiO}_{2}, \alpha$ $\mathrm{Fe}_{2} \mathrm{O}_{3}$, and $\mathrm{ZnO}$ are some of the most typical photoactive materials capable of performing the above-mentioned processes and, accordingly, their properties have been widely studied. $^{10-15}$ In this respect, it has been found that the photoconversion efficiency of these semiconductor materials is limited because of two main reasons. On the one hand, the photogenerated electrons and holes tend to recombine before reaching the surface of the photocatalyst, thus preventing the occurrence of redox reactions. On the other hand, absorption of light is limited, either by being restricted to the UV region of the spectrum and/or by relatively low absorption coefficients. These phenomena make the photoconversion efficiency of semiconductors relatively low for use in large-scale practical applications. ${ }^{16-20}$

During the past years, multiple efforts have been made to increase the photoactive properties of semiconductors. In this regard, the combination of semiconductor materials with plasmonic metal nanoparticles in the same nanostructure, giving rise to the so-called hybrid nanostructures (HNs), constitutes one of the most promising strategies to improving the photoconversion efficiency and to overcoming the drawbacks mentioned above. ${ }^{21-31}$ Plasmonic metal nanoparticles are widely recognized by their unique optical properties, which are characterized by the excitation of localized

Received: December 19, 2017

Revised: February 6, 2018

Published: February 7, 2018 
surface plasmon resonances (LSPRs), which leads to large absorption and scattering cross sections as well as to substantial enhancement of the electric field in the local environment of the plasmonic particle. ${ }^{32-34}$ The progress achieved over the past few years regarding the plasmonic metal-semiconductor interactions leads to the identification of at least three different mechanisms that contribute to enhancing the photoconversion efficiency of a given semiconductor material when it forms part of a $\mathrm{HN}$ : hot electron/hole transfer, light trapping, and plasmon-induced energy transfer based on scattering and nearfield interactions. ${ }^{35-39}$ These mechanisms allow us to increase the speed of generation of electron-hole pairs and can also favor their spatial separation. The intense electric field generated on the surface of the plasmonic metal particle, due to the excitation of the LSPR, is able to significantly increase the generation efficiency of electron-hole pairs in the nearby semiconductor. This process is known as plasmon-induced resonance energy transfer (PIRET) and occurs by the coupling between the dipole moment of the LSPR and the dipole moment of the interband transitions in the semiconductor, resembling in some way the Förster energy transfer mechanism observed between donor and acceptor molecules. ${ }^{35}$ The optimization of the PIRET mechanism requires both spectral and spatial overlaps. That is, the excitation energy of the LSPR should be similar to the bandgap energy of the semiconductor. In addition, the semiconductor component must occupy the spatial region near the plasmonic particle where the most intense near-field enhancements occur. In addition, Cushing et al. have stated that the relative dephasing times of the LSPR and the semiconductor must also be considered for efficient PIRET. ${ }^{37}$ Consequently, electron-hole pairs are produced near the surface of the semiconductor, significantly reducing the recombination of charge carriers during their migration to the catalytic sites at the interface. Nonetheless, although the criterion for optimization of the PIRET mechanism based on spectral and spatial overlaps and on dephasing times of the LSPR is very useful and correctly describes experimental results, it has been obtained from a theoretical methodology that somehow neglects the size-dependent absorption and scattering properties of the nanostructured materials. ${ }^{38}$

Hematite $\left(\alpha-\mathrm{Fe}_{2} \mathrm{O}_{3}\right)$ is the most thermodynamically stable form of iron oxides, and it is environmentally harmless and relatively inexpensive, with an optical bandgap energy between 1.9 and $2.3 \mathrm{eV}$ (corresponding to 650 and $560 \mathrm{~nm}$ wavelengths, respectively) depending on the preparation method. ${ }^{40}$ These properties make $\alpha-\mathrm{Fe}_{2} \mathrm{O}_{3}$ a notable photoanode material for being used in solar energy photoelectrochemical water splitting, a promising route to green and renewable $\mathrm{H}_{2}$ fuel. ${ }^{41-45}$ However, one of the main reasons that limits its performance not only as a water-oxidizing photoanode but also as a heterogeneous photocatalyst for the degradation of pollutants and toxic compounds is the low light-harvesting efficiency. In an effort to improving the photoactive properties, $\alpha$ - $\mathrm{Fe}_{2} \mathrm{O}_{3}$ has been combined with plasmonic metals into $\mathrm{HNs}, \mathrm{Ag}$ and $\mathrm{Au}$ being the typical metals employed. ${ }^{46-48}$ In spite of the multiple complexities from the synthetic point of view, the valuable efforts accomplished regarding the preparation of $\alpha-\mathrm{Fe}_{2} \mathrm{O}_{3} /$ plasmonic metal HNs seem to share in common the lack of guidelines to lead the design of the HNs to optimize their photoactive properties and particularly their light-harvesting efficiency.

In this work, the far- and near-field optical properties of $\alpha$ $\mathrm{Fe}_{2} \mathrm{O}_{3} / \mathrm{M}$ rodlike $\mathrm{HNs}(\mathrm{M}=\mathrm{Ag}, \mathrm{Au}, \mathrm{Al})$ have been studied by means of discrete dipole approximation (DDA) simulations. ${ }^{47-50}$ The HNs studied consist of a $\alpha-\mathrm{Fe}_{2} \mathrm{O}_{3}$ nanocylinder attached concentrically through its base to a metallic nanocylinder, with both components having the same diameter, whereas the length of the metallic component, $L$, was varied systematically in a broad range. In addition, to carry out this study, an strategy was implemented that allowed us to examine the contribution of each component of the $\mathrm{HN}$ to the absorption efficiency, $Q_{\mathrm{abs}}$, separately. Furthermore, on the basis of the $Q_{\text {abs }}$ values, it was possible to calculate the absorbed photon flux within the $\alpha-\mathrm{Fe}_{2} \mathrm{O}_{3}$ component, $\phi$, the relevant quantity that greatly determines the photoconversion efficiency of photoelectrochemical cells and photocatalysts. It is shown that the absorbed photon flux within the $\alpha-\mathrm{Fe}_{2} \mathrm{O}_{3}$ component, $\phi$, presents a strong dependence on the length of the metallic counterpart, $L$, indicating that it is possible to significantly improve the photoactive properties of HNs by a proper tuning of its dimensions. In addition, it is also shown that the $\phi$ values can be largely modified by changing the nature of the plasmonic metal that constitutes the $\mathrm{HN}$. With the aim to obtaining more accurate criteria able to guide the design toward the maximization of the photoactive properties of HNs, it was empirically found, for all three plasmonic metals studied, that the $\phi$ values directly correlate with a parameter determined by the interplay between the bandgap energy of $\alpha$ - $\mathrm{Fe}_{2} \mathrm{O}_{3}$ and the energy and radiative line width of the LSPR. Note that issues related to the phenomena subsequent to light absorption (kinetics of chemical reactions, diffusion length of charge carriers, and overpotential requirements) are not addressed in the present work. We believe that the results presented in this work provide valuable information for an efficient design of HNs with improved photoactive properties.

\section{THEORY AND COMPUTATIONAL DETAILS}

In this work, the far- and near-field optical properties of HNs composed of $\alpha-\mathrm{Fe}_{2} \mathrm{O}_{3}$ and a metallic counterpart have been systematically studied by means of DDA simulations. To perform this study, we have employed the DDSCAT 7.3 code, which implements the DDA method in such a way as to assess the absorption efficiency, $Q_{a b s}$, spectrum from each component of the HN separately. ${ }^{49}$ Details about this methodology can be found elsewhere. ${ }^{50-53}$ Briefly, in this method, the object of interest is approximately represented by a cubic array of $N$ dipoles at positions $r_{\mathrm{i}}$ with dipole polarizabilities $\alpha_{\mathrm{i}}$. The dipoles can be distributed inside the cubic array without restrictions and, consequently, the properties of arbitrarily shaped particles can be simulated. Dipole polarizability $\alpha_{\mathrm{i}}$ at each dipole position $r_{\mathrm{i}}$ is determined on the basis of the lattice dispersion relation and the dielectric constant of the composition material at position $r_{\mathrm{i}}$, which is introduced as input, allowing the simulation of optical properties of nanostructures with domains having different compositions. A key parameter in this methodology is the number of dipoles, $N$, used to represent the object under study because both the precision of the simulation and the computational time increase with $N$. Therefore, the value of $N$ selected to represent a given nanostructure must comply with the tolerance of acceptable error.

The methodology applied in this work allows us to calculate the absorption efficiency, $Q_{\mathrm{abs}}$, spectrum for each component of the $\mathrm{HN}$, that is, the $\alpha-\mathrm{Fe}_{2} \mathrm{O}_{3}$ rod and the metallic counterpart, according to the following expression ${ }^{54}$ 


$$
Q_{\mathrm{abs}, \mathrm{i}}=\frac{k \operatorname{Im}(\varepsilon(\lambda))}{C_{\text {geom }}\left|E_{0}\right|^{2}} \int_{V_{\mathrm{i}}}\left|E\left(r_{\mathrm{i}}\right)\right|^{2} \mathrm{~d} r
$$

where $\operatorname{Im}(\varepsilon(\lambda))$ is the value of the wavelength $(\lambda)$-dependent imaginary part of the dielectric constant of the material at position $r_{\mathrm{i}}, C_{\text {geom }}$ is the projected area of the HN perpendicular to $k$, and $E\left(r_{\mathrm{i}}\right)$ is the electric field values calculated at each dipole position $r_{\mathrm{i}}$. In addition, the integral is calculated over volume $V_{\mathrm{i}}$ occupied by material $\mathrm{i}$, that is, by $\alpha-\mathrm{Fe}_{2} \mathrm{O}_{3}$ or the metallic rod, for each wavelength of interest.

The HNs studied in this work are composed of a $\alpha-\mathrm{Fe}_{2} \mathrm{O}_{3}$ cylinder in contact through its base to a metallic cylinder. Both components have a diameter of $50 \mathrm{~nm}$, the length of the $\alpha$ $\mathrm{Fe}_{2} \mathrm{O}_{3}$ rod is $50 \mathrm{~nm}$, and the length of the metallic component, $L$, has been varied in the $0-100 \mathrm{~nm}$ range. In addition, the HNs studied are composed of three different metallic counterparts: $\mathrm{Au}, \mathrm{Ag}$, and $\mathrm{Al}$. Figure 1 schematically illustrates the HNs

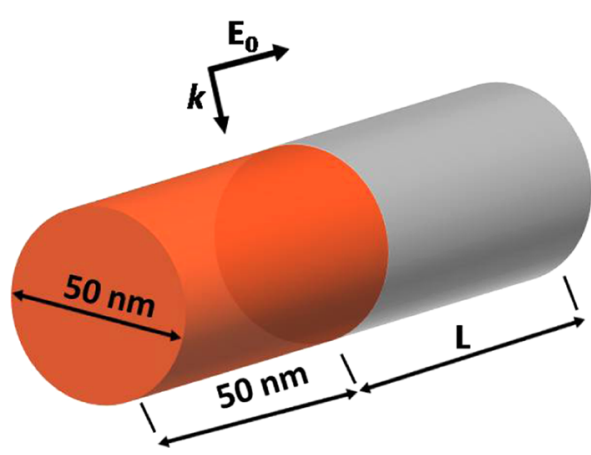

Figure 1. Schematic representation of the $\alpha-\mathrm{Fe}_{2} \mathrm{O}_{3} / \mathrm{M}$ rodlike hybrid nanostructures studied in this work $(\mathrm{M}=\mathrm{Ag}, \mathrm{Au}$, and $\mathrm{Al})$. Electric field $E_{0}$ and wave vector $k$ of the incident light are parallel and perpendicular to the rod axis, respectively. Both components have a diameter of $50 \mathrm{~nm}$, the length of the $\alpha-\mathrm{Fe}_{2} \mathrm{O}_{3}$ rod is $50 \mathrm{~nm}$, and the length of the metallic component $L$ has been varied in the $0-100 \mathrm{~nm}$ range.

investigated, along with the orientations of electric field $E_{0}$ and wave vector $k$ of the incident light relative to the HN. Unless otherwise specified explicitly, $E_{0}$ is parallel, whereas $k$ is perpendicular to the major axis of the $\mathrm{HN}$ for all cases studied.

The wavelength-dependent complex dielectric constants of $\alpha-\mathrm{Fe}_{2} \mathrm{O}_{3}$ with $\mathrm{Al}, \mathrm{Ag}$, and $\mathrm{Au}$ were obtained from refs 55, 56, and 57 respectively. The number of dipoles, $N$, employed in the simulations varied from $1 \times 10^{5}$ to $3 \times 10^{5}$ according to the
HN dimensions in such a way that a lattice spacing (interdipole distance) of $1.5 \mathrm{~nm}$ was set in all simulations. In addition, the dielectric properties of the environment were set equal to those of water in all cases.

\section{RESULTS AND DISCUSSION}

Far- and Near-Field Optical Properties of $\alpha-\mathrm{Fe}_{2} \mathrm{O}_{3} / \mathrm{Ag}$ HNs. Effect of Ag Rod Length L on Absorption Efficiency $Q_{a b s}$. Figure 2 shows absorption efficiency, $Q_{a b s}$, spectra of $\alpha$ $\mathrm{Fe}_{2} \mathrm{O}_{3} / \mathrm{Ag} \mathrm{HNs}$ composed of $\mathrm{Ag}$ rods of increasing length $L$. In all cases, the diameter of both components is $50 \mathrm{~nm}$ and the length of the $\alpha-\mathrm{Fe}_{2} \mathrm{O}_{3}$ component is $50 \mathrm{~nm}$. The $Q_{\text {abs }}$ spectrum of the $\mathrm{HN}$ with a $\mathrm{Ag}$ rod of length $30 \mathrm{~nm}$ (Figure 2a, black curve) presents a defined peak centered at $465 \mathrm{~nm}$, whose contributions to it from the $\mathrm{Ag}$ and $\alpha-\mathrm{Fe}_{2} \mathrm{O}_{3}$ components are also plotted as blue and red curves, respectively. The $Q_{\text {abs }}$ spectrum of the Ag rod shows a peak located at $450 \mathrm{~nm}$, which is attributed to the excitation of the LSPR, whereas the $Q_{\text {abs }}$ spectrum of the $\alpha-\mathrm{Fe}_{2} \mathrm{O}_{3}$ component exhibits a peak at $475 \mathrm{~nm}$, both contributions having similar intensities. In addition, the $Q_{\text {abs }}$ spectrum of the $\mathrm{HN}$ with $L=0 \mathrm{~nm}$, that is, the spectrum of a $\alpha-\mathrm{Fe}_{2} \mathrm{O}_{3}$ rod with identical dimensions and without the metallic counterpart, is also shown (green curve). The $Q_{\mathrm{abs}}$ of the isolated $\alpha-\mathrm{Fe}_{2} \mathrm{O}_{3}$ rod decreases almost linearly from 400 up to $600 \mathrm{~nm}$, and for $\lambda>600 \mathrm{~nm}$ its values are practically negligible. By comparing the spectra shown as red and green curves, the noticeable influence of the Ag rod on the absorption properties of the $\alpha-\mathrm{Fe}_{2} \mathrm{O}_{3}$ rod can be clearly appreciated. Indeed, the absorption efficiency of the $\alpha-\mathrm{Fe}_{2} \mathrm{O}_{3}$ rod substantially increases when it is in contact with the Ag rod. As the $\mathrm{Ag}$ rod length is increased from 30 to $50 \mathrm{~nm}$, the $Q_{\mathrm{abs}}$ spectrum of the $\mathrm{NH}$ presents a more intense peak located at $550 \mathrm{~nm}$ (Figure 2b, black curve). This effect is mainly due to the red shift of the LSPR of the Ag rod, which is centered now at $550 \mathrm{~nm}$ (Figure 2b, blue curve), a rather expected result in agreement with previous studies. ${ }^{58}$ On the other hand, it is also observed that the absorption from the $\alpha-\mathrm{Fe}_{2} \mathrm{O}_{3}$ component (Figure 2b, red curve) shows a peak at $540 \mathrm{~nm}$ and is much larger than that corresponding to the isolated $\alpha-\mathrm{Fe}_{2} \mathrm{O}_{3}$ rod (Figure $2 b$, green curve). A further increase in the length of $\mathrm{Ag}$ rod, $L$, to $70 \mathrm{~nm}$ produces an additional red shift of the LSPR to $630 \mathrm{~nm}$ (Figure 2c, blue curve), which in turn dominates the $Q_{\text {abs }}$ spectrum of the $\mathrm{HN}$ as a whole (Figure 2c, black curve). In addition, the $Q_{\text {abs }}$ spectrum of the $\alpha-\mathrm{Fe}_{2} \mathrm{O}_{3}$ component (Figure $2 c$, red curve) shows larger $Q_{a b s}$ values than the respective values for the isolated $\alpha-\mathrm{Fe}_{2} \mathrm{O}_{3}$ rod (Figure 2c, green curve) in
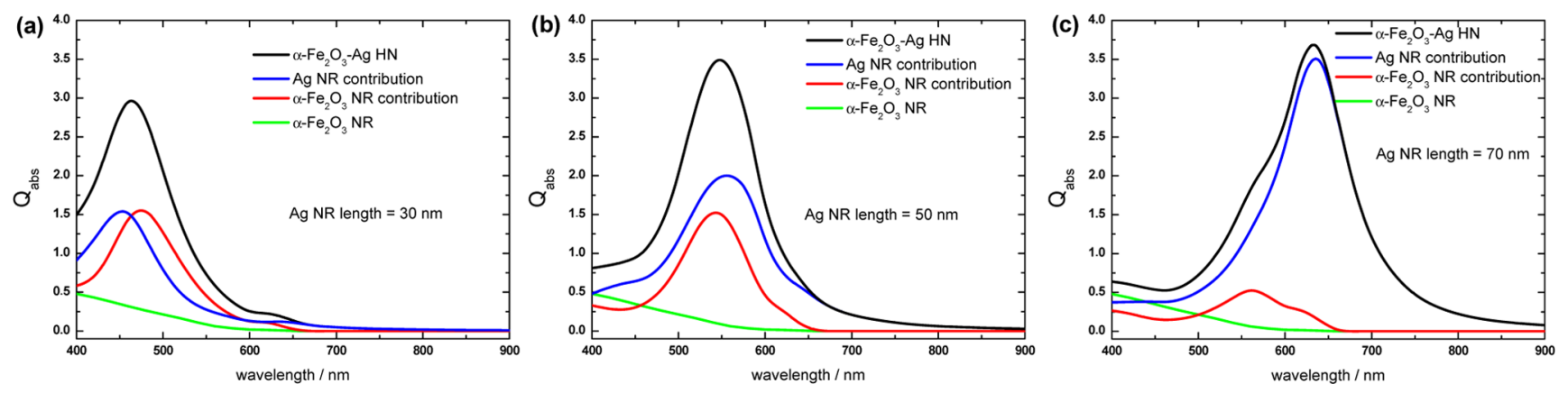

Figure 2. Absorption efficiency, $\mathrm{Q}_{\mathrm{abs}}$, spectra of $\alpha$ - $\mathrm{Fe}_{2} \mathrm{O}_{3} / \mathrm{Ag} \mathrm{HNs}$ (black curves) along with the respective contributions from the $\alpha$ - $\mathrm{Fe}_{2} \mathrm{O}_{3}$ (red curves) and $\mathrm{Ag}$ (blue curves) components. The diameter of both components is $50 \mathrm{~nm}$ in all cases. The length of the $\alpha$ - $\mathrm{Fe}_{2} \mathrm{O}_{3}$ component is $50 \mathrm{~nm}$ in all cases, whereas the lengths, $L$, of the Ag component are (a) 30, (b) 50, and (c) $70 \mathrm{~nm}$. For comparison, the $Q_{\text {abs }}$ spectrum of an isolated $\alpha$ $\mathrm{Fe}_{2} \mathrm{O}_{3} \operatorname{rod}(L=0 \mathrm{~nm})$ is also shown (green curve). 
(a)

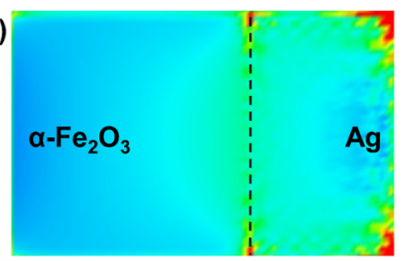

(b)

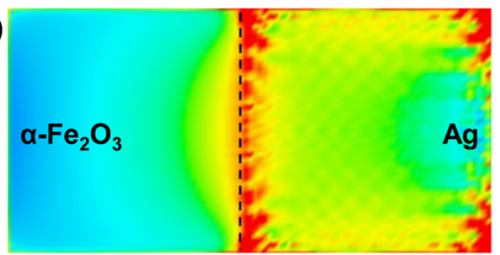

(c)

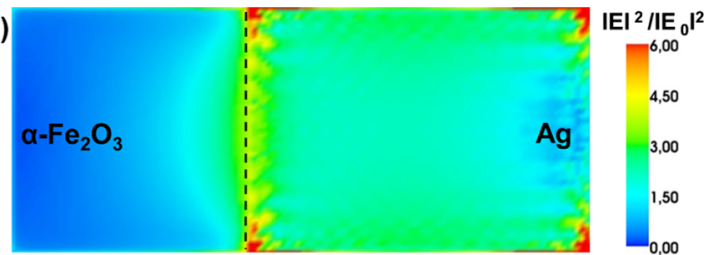

Figure 3. Near-field patterns of $\alpha$ - $\mathrm{Fe}_{2} \mathrm{O}_{3} / \mathrm{Ag} \mathrm{HNs}$ through planes that contain the main axis of the $\mathrm{HN}$ and wave vector $k$, under an excitation wavelength of $540 \mathrm{~nm}$. The left and right parts of each panel represent the $\alpha-\mathrm{Fe}_{2} \mathrm{O}_{3}$ and $\mathrm{Ag}$ components, respectively, whereas the dashed black lines represent the interface between them. The diameter of both components is $50 \mathrm{~nm}$ in all cases. The length of the $\alpha$ - $\mathrm{Fe}_{2} \mathrm{O}_{3}$ component is $50 \mathrm{~nm}$ in all cases, whereas the lengths, $L$, of the Ag component are (a) 30, (b) 50, and (c) $70 \mathrm{~nm}$.
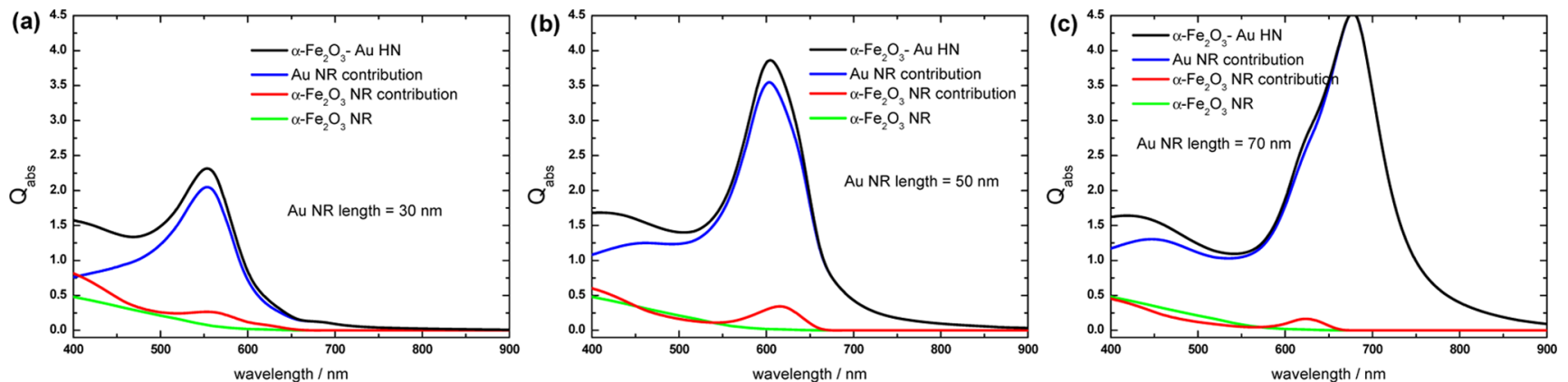

Figure 4. Absorption efficiency, $\mathrm{Q}_{\mathrm{abs}}$, spectra of $\alpha-\mathrm{Fe}_{2} \mathrm{O}_{3} / \mathrm{Au} \mathrm{HNs}$ (black curves) along with the respective contributions from the $\alpha$ - $\mathrm{Fe}_{2} \mathrm{O}_{3}$ (red curves) and $\mathrm{Au}$ (blue curves) components. The diameter of both components is $50 \mathrm{~nm}$ in all cases. The length of the $\alpha$-Fe $\mathrm{O}_{2} \mathrm{O}_{3}$ component is $50 \mathrm{~nm}$ in all cases, whereas the lengths, $L$, of the Au component are (a) 30, (b) 50, and (c) $70 \mathrm{~nm}$. For comparison, the $Q_{\mathrm{abs}}$ spectrum of an isolated $\alpha$ $\mathrm{Fe}_{2} \mathrm{O}_{3}$ rod $(L=0 \mathrm{~nm})$ is also shown (green curve).

the 500-650 $\mathrm{nm}$ spectral range but smaller intensity in comparison to that in the previous cases. Therefore, in general, it is observed that the $Q_{\mathrm{abs}}$ values of the $\alpha-\mathrm{Fe}_{2} \mathrm{O}_{3}$ component are larger than the respective values for the isolated $\alpha-\mathrm{Fe}_{2} \mathrm{O}_{3}$ rod and that they strongly depend on the length of the $\mathrm{Ag}$ rod, $L$.

Effect of Ag Rod Length L on the Near-Field Intensity and Distribution. To achieve a deeper comprehension of the phenomena described above, the far-field properties are correlated with near-field properties. Figure 3 shows nearfield patterns of $\alpha-\mathrm{Fe}_{2} \mathrm{O}_{3} / \mathrm{Ag} \mathrm{HNs}$ composed of $\mathrm{Ag}$ rods of increasing length $L$ through planes that contain the main axis of the $\mathrm{HN}$ and wave vector $k$. In all cases, the patterns correspond to illumination of the HNs with a wavelength of $540 \mathrm{~nm}$. The choice of an excitation wavelength fixed at $540 \mathrm{~nm}$, as a convenient value to analyze the near-field patterns of the HNs of different compositions and sizes studied in this work, arises after considering jointly the hematite absorption range, the range where the incident spectral photon flux $I(\lambda)$ presents the largest values, and the respective plasmon resonance wavelengths. The left and right parts of each panel represent the $\alpha$ $\mathrm{Fe}_{2} \mathrm{O}_{3}$ and $\mathrm{Ag}$ components, respectively, whereas the dashed black lines schematically represent the interface between them. It can be clearly appreciated that the intensity and distribution of the near field within the $\alpha-\mathrm{Fe}_{2} \mathrm{O}_{3}$ component strongly depend on the $\mathrm{Ag}$ rod length. For instance, for a $\mathrm{Ag}$ rod of length $L=30 \mathrm{~nm}$ (Figure 3a), the near-field distribution within $\alpha-\mathrm{Fe}_{2} \mathrm{O}_{3}$ is quite homogeneous and its values show slight enhancement. However, for $L=50 \mathrm{~nm}$ (Figure 3b), the $\alpha$ $\mathrm{Fe}_{2} \mathrm{O}_{3}$ component shows significant near-field enhancement, which is mostly concentrated in those spatial regions close to the Ag rod specially at the interphase. A further increase in the length, $L$, of the $\mathrm{Ag}$ rod to $70 \mathrm{~nm}$ (Figure 3c) leads to an inhomogeneous near-field distribution within the $\alpha-\mathrm{Fe}_{2} \mathrm{O}_{3}$ component, the values being moderately high in the region in contact with the Ag rod, which rapidly decrease upon moving away from the interface.

Importantly, note that at $540 \mathrm{~nm}$ the LSPR of the Ag rod with $L=50 \mathrm{~nm}$ is on-resonance (see Figure $2 \mathrm{~b}$ ), whereas that of the HNs with lengths of the Ag rod of 30 and $70 \mathrm{~nm}$, the LSPR is off-resonance (see Figure 2a,c, respectively). Therefore, the variation of the electric field values within the $\alpha-\mathrm{Fe}_{2} \mathrm{O}_{3}$ component is attributed to the excitation of the LSPR in the $\mathrm{Ag}$ counterpart of the HN. Furthermore, according to eq 1 , the enhancements of the electric field within the $\alpha-\mathrm{Fe}_{2} \mathrm{O}_{3}$ component explain the increase in the respective $Q_{a b s}$ values. These results clearly exemplify the relevance of optimizing the structural design of $\mathrm{HNs}$ to improve their photoactive properties given that, among others parameters, the spectral position of the LSPR depends on the metallic component dimensions. The near-field patterns of $\alpha-\mathrm{Fe}_{2} \mathrm{O}_{3} / \mathrm{Ag} \mathrm{HNs}$ excited at their respective plasmon resonance wavelengths are provided in Figure S1.

Far- and Near-Field Optical Properties of $\alpha-\mathrm{Fe}_{2} \mathrm{O}_{3} / \mathrm{Au}$ HNs. Effect of Au Rod Length L on Absorption Efficiency $Q_{a b s}$. The optical properties of $\alpha-\mathrm{Fe}_{2} \mathrm{O}_{3} / \mathrm{Au} \mathrm{HNs}$ have also been simulated to establish similarities and differences between the optical responses of HNs composed of distinct plasmonic metals. Figure 4 shows the absorption efficiency, $Q_{\mathrm{abs}}$, spectra of $\alpha-\mathrm{Fe}_{2} \mathrm{O}_{3} / \mathrm{Au} \mathrm{HNs}$ composed of $\mathrm{Au}$ rods of increasing length $L$. In general, it is observed that the absorption spectra of the $\mathrm{HN}$ (Figure 4, black curves) present a defined peak whose intensity increases and spectral position red-shifts as the Au rod length, $L$, increases from (a) 30 to (b) 50 and to (c) $70 \mathrm{~nm}$. Furthermore, the absorption spectra of the HN are mostly given by the contribution from the $\mathrm{Au}$ rod (Figure 4, blue curves). On the other hand, the contribution of the $\alpha-\mathrm{Fe}_{2} \mathrm{O}_{3}$ component to the absorption spectra also presents a peak 

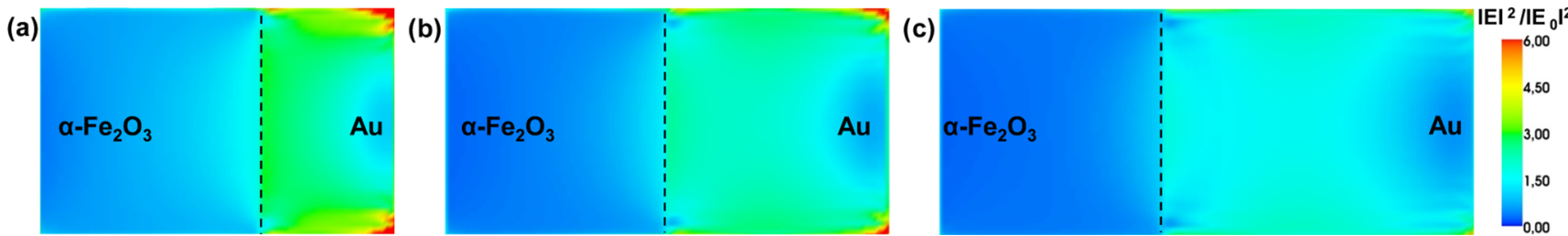

Figure 5. Near-field patterns of $\alpha-\mathrm{Fe}_{2} \mathrm{O}_{3} / \mathrm{Au} \mathrm{HNs}$ through planes that contain the main axis of the $\mathrm{HN}$ and wave vector $k$, under an excitation wavelength of $540 \mathrm{~nm}$. The left and right parts of each panel represent the $\alpha-\mathrm{Fe}_{2} \mathrm{O}_{3}$ and Au components, respectively, whereas the dashed black lines represent the interface between them. The diameter of both components is $50 \mathrm{~nm}$ in all cases. The length of the $\alpha$ - $\mathrm{Fe}_{2} \mathrm{O}_{3}$ component is $50 \mathrm{~nm}$ in all cases, whereas the lengths, $L$, of the Au component are (a) 30, (b) 50, and (c) $70 \mathrm{~nm}$.
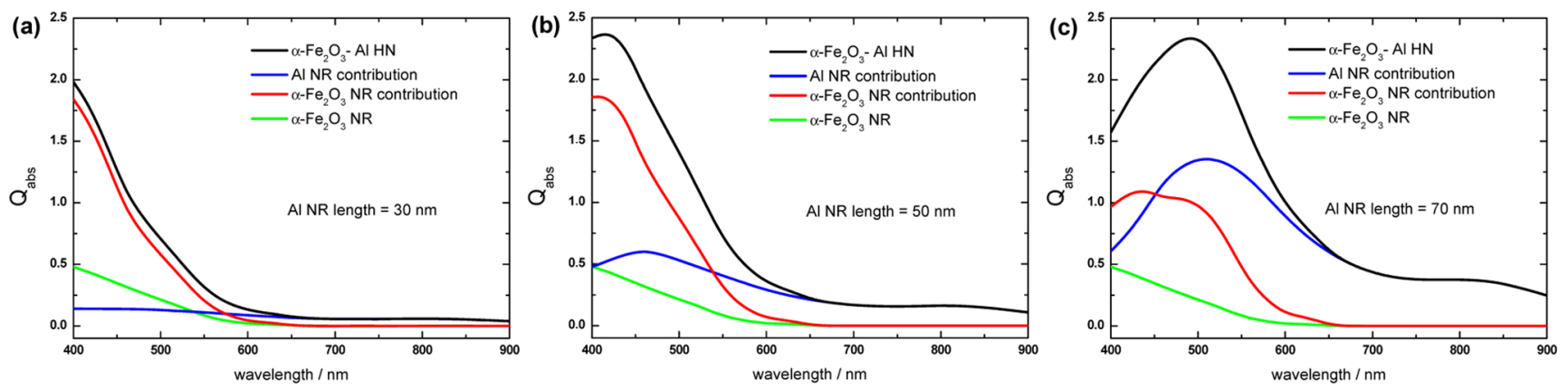

Figure 6. Absorption efficiency, $\mathrm{Q}_{\mathrm{abs}}$, spectra of $\alpha$ - $\mathrm{Fe}_{2} \mathrm{O}_{3} / \mathrm{Al} \mathrm{HNs}$ (black curves) along with the respective contributions from the $\alpha$ - $\mathrm{Fe}_{2} \mathrm{O}_{3}(\mathrm{red}$ curves) and $\mathrm{Al}$ (blue curves) components. The diameter of both components is $50 \mathrm{~nm}$ in all cases. The length of the $\alpha$ - $\mathrm{Fe}_{2} \mathrm{O}_{3}$ component is $50 \mathrm{~nm}$ in all cases, whereas the lengths, $L$, of the $\mathrm{Al}$ component are (a) 30, (b) 50, and (c) $70 \mathrm{~nm}$. For comparison, the $Q_{\mathrm{abs}}$ spectrum of an isolated $\alpha$-Fe $\mathrm{O}_{2}$ $\operatorname{rod}(L=0 \mathrm{~nm})$ is also shown (green curve).

whose spectral position shifts to larger wavelengths as the $\mathrm{Au}$ rod length increases. These trends resemble those described for the $\alpha-\mathrm{Fe}_{2} \mathrm{O}_{3} / \mathrm{Ag} \mathrm{HNs}$. However, a quantitative difference arises regarding the absorption intensity of the $\alpha-\mathrm{Fe}_{2} \mathrm{O}_{3}$ component. Importantly, the $Q_{\mathrm{abs}}$ values for the $\alpha-\mathrm{Fe}_{2} \mathrm{O}_{3}$ component (Figure 4, red curves) are quite similar to those corresponding to the $\alpha-\mathrm{Fe}_{2} \mathrm{O}_{3}$ rod with identical dimensions and without the metallic counterpart (Figure 4, green curves) and are substantially smaller than those found when the metallic counterpart of the $\mathrm{HN}$ is $\mathrm{Ag}$ (see Figure 3, green curves). In fact, the $Q_{\text {abs }}$ peak values of the $\alpha-\mathrm{Fe}_{2} \mathrm{O}_{3}$ component decrease roughly from 1.5 to 0.5 when $\mathrm{Ag}$ is replaced with $\mathrm{Au}$ as the metallic counterpart of the $\mathrm{HN}$, indicating that $\mathrm{Ag}$ is more suitable than Au to enhance the light-harvesting properties in $\alpha$ $\mathrm{Fe}_{2} \mathrm{O}_{3}$. The possible reasons that might explain this different behavior will be further analyzed and discussed in the next section.

Effect of Au Rod Length $L$ on the Near-Field Intensity and Distribution. The near-field patterns of $\alpha-\mathrm{Fe}_{2} \mathrm{O}_{3} / \mathrm{Au} \mathrm{HNs}$ composed of Au rods of increasing length $L$ through planes that contain the main axis of the $\mathrm{HN}$ and wave vector $k$ are shown in Figure 5. In all cases, the patterns correspond to illumination of the HNs with a wavelength of $540 \mathrm{~nm}$. The left and right parts of each panel represent the $\alpha-\mathrm{Fe}_{2} \mathrm{O}_{3}$ and $\mathrm{Au}$ components, respectively, whereas the dashed black lines schematically represent the interface between them. In this case, the distribution of near field within the $\alpha-\mathrm{Fe}_{2} \mathrm{O}_{3}$ component is similar to that found in the previous case, that is, the largest values are concentrated in the proximity of the interface between $\alpha-\mathrm{Fe}_{2} \mathrm{O}_{3}$ and $\mathrm{Au}$. Nonetheless, a significant enhancement of the electric field is not observed, whatever the length of the $\mathrm{Au}$ rod. This observation explains, according to eq 1 , the relatively low $Q_{\text {abs }}$ values observed for the $\alpha-\mathrm{Fe}_{2} \mathrm{O}_{3}$ component (see Figure 4, red curves). Note that at an excitation wavelength of $540 \mathrm{~nm}$, the LSPR is off-resonance for the $\mathrm{HNs}$ with $\mathrm{Au}$ rod lengths of 50 and $70 \mathrm{~nm}$, and, on the contrary, the LSPR is on-resonance for the HN with Au rod length of $30 \mathrm{~nm}$ (see Figure 4, blue curves). However, the electric field enhancement within the $\alpha-\mathrm{Fe}_{2} \mathrm{O}_{3}$ component for $L$ $=30 \mathrm{~nm}$ is fairly poor in comparison to the values found for $\mathrm{Ag}$ (see Figure 3). This result might seem opposite to intuition given that the LSPR is on-resonance and shows that the optimization of light absorption by a semiconductor material goes beyond the mere spectral overlap and therefore it should require to take into account the interplay between several factors. The near-field patterns of $\alpha$ - $\mathrm{Fe}_{2} \mathrm{O}_{3} / \mathrm{Au} \mathrm{HNs}$ excited at their respective plasmon resonance wavelengths are provided in Figure S2.

Far- and Near-Field Optical Properties of $\alpha-\mathrm{Fe}_{2} \mathrm{O}_{3} / \mathrm{Al}$ HNs. Effect of Al Rod Length L on Absorption Efficiency $Q_{a b s}$. The third type of HNs studied in this work are those composed of $\mathrm{Al}$ as the metallic counterpart. The absorption efficiency, $Q_{\mathrm{abs}}$, spectra of $\alpha-\mathrm{Fe}_{2} \mathrm{O}_{3} / \mathrm{Al} \mathrm{HNs}$ composed of $\mathrm{Al}$ rods of increasing length $L$ are shown in Figure 6. For $L=30 \mathrm{~nm}$, the $Q_{\mathrm{abs}}$ spectrum of the $\mathrm{Al}$ rod exhibits low values and presents no appreciable peak in the wavelength range studied (Figure 6a, blue curve). It is speculated that, due to the relatively small size of the rod along with the intrinsic dielectric properties of $\mathrm{Al}$, the LSPR is spectrally located at higher energies, that is, at wavelengths shorter than $400 \mathrm{~nm}$. The contribution to the $Q_{\mathrm{abs}}$ spectrum of the $\alpha-\mathrm{Fe}_{2} \mathrm{O}_{3}$ component (Figure 6a, red curve) practically dominates the spectrum of the $\mathrm{HN}$ as a whole (Figure 6a, black curve) and, despite the fact that the LSPR is apparently not excited, its intensity is notably enhanced in comparison to that of the spectrum of the isolated $\alpha-\mathrm{Fe}_{2} \mathrm{O}_{3}$ rod (Figure 6a, green curve). As the $\mathrm{Al}$ rod length is increased to $L$ $=50 \mathrm{~nm}$, a peak centered at $450 \mathrm{~nm}$ appears in the $Q_{\mathrm{abs}}$ spectrum, which is attributed to the contribution coming from 
(a)

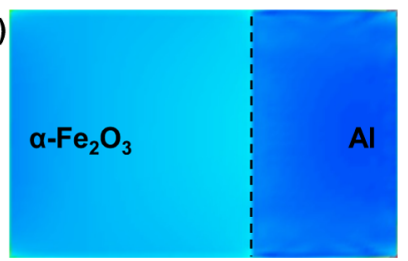

(b)

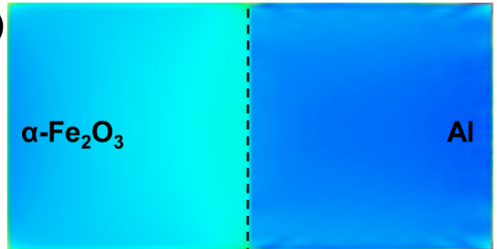

(c)

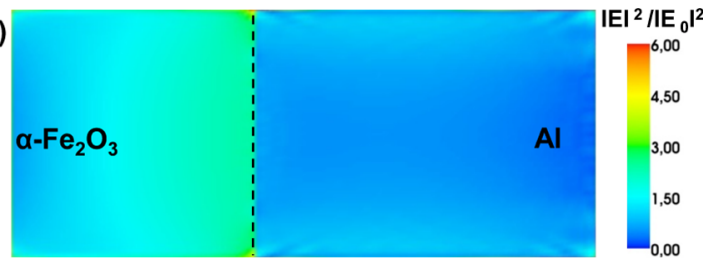

Figure 7. Near-field patterns of $\alpha$ - $\mathrm{Fe}_{2} \mathrm{O}_{3} / \mathrm{Al} \mathrm{HNs}$ through planes that contain the main axis of the $\mathrm{HN}$ and wave vector $k$, under an excitation wavelength of $540 \mathrm{~nm}$. The left and right parts of each panel represent the $\alpha-\mathrm{Fe}_{2} \mathrm{O}_{3}$ and Al components, respectively, whereas the dashed black lines represent the interface between them. The diameter of both components is $50 \mathrm{~nm}$ in all cases. The length of the $\alpha$ - $\mathrm{Fe}_{2} \mathrm{O}_{3}$ component is $50 \mathrm{~nm}$ in all cases, whereas lengths $L$ of the $\mathrm{Al}$ component are (a) 30, (b) 50, and (c) $70 \mathrm{~nm}$.
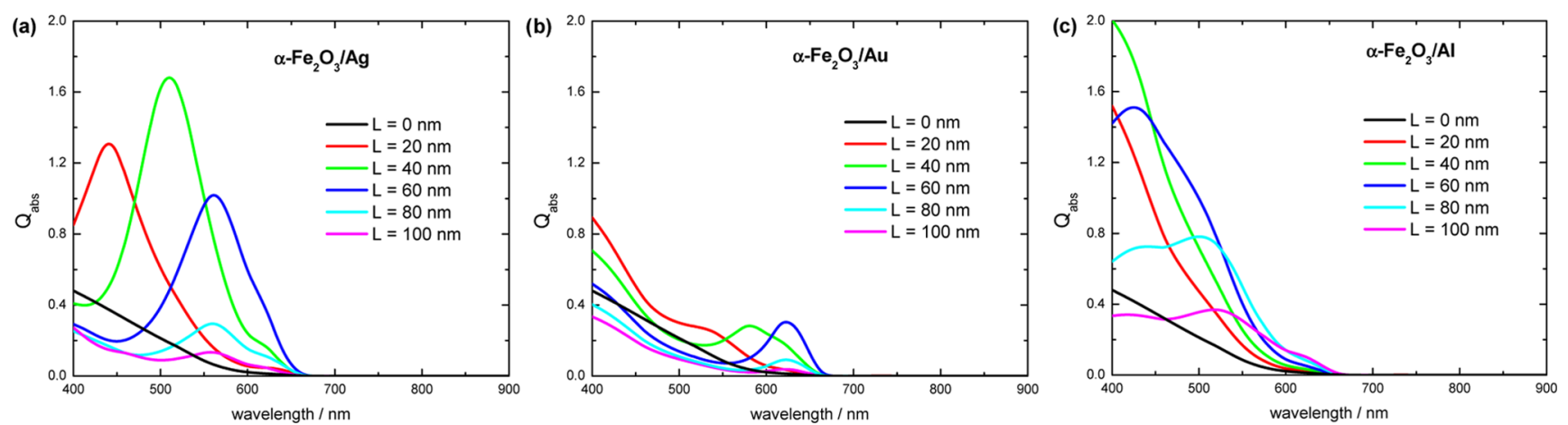

Figure 8. Variation of the absorption efficiency, $\mathrm{Q}_{\mathrm{abs}}$, spectrum of the $\alpha$ - $\mathrm{Fe}_{2} \mathrm{O}_{3}$ component of $\alpha-\mathrm{Fe}_{2} \mathrm{O}_{3} / \mathrm{M}$ HNs with a metallic rod of length $L$, where (a) $\mathrm{M}=\mathrm{Ag}$, (b) $\mathrm{M}=\mathrm{Au}$, and (c) $\mathrm{M}=\mathrm{Al}$. The diameter of both components is $50 \mathrm{~nm}$, and the length of the $\alpha$ - $\mathrm{Fe}_{2} \mathrm{O}_{3}$ component is $50 \mathrm{~nm}$ in all cases. The length, $L$, of the metallic component, $M$, is varied in the $0-100 \mathrm{~nm}$ range.

the excitation of the LSPR of the $\mathrm{Al}$ rod (Figure $6 \mathrm{~b}$, blue curve). In addition, the partial contribution of the $\alpha-\mathrm{Fe}_{2} \mathrm{O}_{3}$ component to the $Q_{a b s}$ spectrum (Figure $6 \mathrm{~b}$, red curve) presents a peak near $400 \mathrm{~nm}$, their values being noticeably larger than those corresponding to the isolated $\alpha-\mathrm{Fe}_{2} \mathrm{O}_{3}$ rod (Figure 6b, green curve).

An additional increase in the $\mathrm{Al}$ rod length to $70 \mathrm{~nm}$ leads to an increase in the intensity and a red shift of the $Q_{\text {abs }}$ peak, attributed to the LSPR of the $\mathrm{Al}$ rod (Figure 6c, blue curve). In addition, the $Q_{\mathrm{abs}}$ spectrum of the $\alpha-\mathrm{Fe}_{2} \mathrm{O}_{3}$ component (Figure $6 c$, red curve) becomes broader, showing larger values than those for the isolated $\alpha-\mathrm{Fe}_{2} \mathrm{O}_{3}$ rod (Figure 6b, green curve). Importantly, note the remarkable decrease of the $Q_{\mathrm{abs}}$ contribution of the $\alpha-\mathrm{Fe}_{2} \mathrm{O}_{3}$ component in the $400-450 \mathrm{~nm}$ range as the $\mathrm{Al}$ rod length, $L$, increases from 50 to $70 \mathrm{~nm}$, that is, as the spectral position of the LSPR red-shifts from 460 to $510 \mathrm{~nm}$. Thus, the results presented in Figure 6 clearly show that light harvesting in $\alpha$ - $\mathrm{Fe}_{2} \mathrm{O}_{3}$ can be strongly enhanced when it is coupled with $\mathrm{Al}$ in the $\mathrm{HN}$ as a consequence of the excitation of LSPR in the metallic Al rod.

Effect of Al Rod Length $L$ on the Near-Field Intensity and Distribution. Figure 7 shows near-field patterns of $\alpha-\mathrm{Fe}_{2} \mathrm{O}_{3} / \mathrm{Al}$ $\mathrm{HNs}$ composed of $\mathrm{Al}$ rods of increasing length $L$ through planes that contain the main axis of the HN and wave vector $k$. In all cases, the patterns correspond to illumination of the HNs with a wavelength of $540 \mathrm{~nm}$. In general, it can be observed that, whatever the length of the $\mathrm{Al} \mathrm{rod}$, the distribution of the near field within the $\alpha-\mathrm{Fe}_{2} \mathrm{O}_{3}$ component is more homogenous, in contrast to that in the $\mathrm{Ag}$ and $\mathrm{Au}$ HNs. The electric field enhancement is not concentrated mainly at the interface, and its values decrease more slowly upon moving away from the interface between the components of the HN. Furthermore, the values of the enhancements of the electric field are intermediate between those found for Ag (Figure 3) and Au (Figure 5). In addition, the near-field enhancement within $\alpha$ - $\mathrm{Fe}_{2} \mathrm{O}_{3}$ increases as $\mathrm{Al}$ rod length $L$ increases or, alternatively, as the spectral position of the LSPR red-shifts approaching $540 \mathrm{~nm}$. This observation indicates that the enhancement of the electric field within the $\alpha-\mathrm{Fe}_{2} \mathrm{O}_{3}$ component, and consequently the increase of $Q_{\mathrm{abs}}$, is intimately related to the excitation of the LSPR in the metallic counterpart of the HN. The near-field patterns of $\alpha$ $\mathrm{Fe}_{2} \mathrm{O}_{3} / \mathrm{Al} \mathrm{HNs}$ excited at their respective plasmon resonance wavelengths are provided in Figure S3.

Effect of the Metallic Counterpart on Absorption Efficiency $Q_{a b s}$. Figure 8 shows absorption efficiency, $Q_{a b s}$, spectra of the $\alpha-\mathrm{Fe}_{2} \mathrm{O}_{3}$ component for different metallic rod lengths, which allow us to compare the effects of the three different metals studied in this work on the magnitude of the light absorption enhancement. At first glance, it can be appreciated that the main effect of $\mathrm{Ag}$ (Figure 8a) and $\mathrm{Al}$ (Figure $8 \mathrm{c}$ ) is the significant increase in the absorption contribution of the $\alpha-\mathrm{Fe}_{2} \mathrm{O}_{3}$ component compared to that of the isolated $\alpha-\mathrm{Fe}_{2} \mathrm{O}_{3} \operatorname{rod}(L=0 \mathrm{~nm})$, whereas $\mathrm{Au}$ (Figure $8 \mathrm{~b}$ ) leads to a moderate enhancement. In the case of $\mathrm{Ag}$, the partial contribution to $Q_{\mathrm{abs}}$ from $\alpha-\mathrm{Fe}_{2} \mathrm{O}_{3}$ shows large values up to a rod length of $60 \mathrm{~nm}$, whereas for larger $L$ values, the absorption spectrum depicts a remarkable decrease in its intensity.

It is important to correlate this observation with the plasmon resonance wavelength for each $L$ value (see Table 1 ). Note that the $Q_{\mathrm{abs}}$ values for the $\alpha-\mathrm{Fe}_{2} \mathrm{O}_{3}$ component decrease when the LSPR wavelength is red-shifted beyond $600 \mathrm{~nm}$, that is, for wavelengths where $\operatorname{Im}\left(\varepsilon(\lambda)_{\alpha-\mathrm{Fe}_{2} \mathrm{O}_{3}}\right) \rightarrow 0 .^{21} \mathrm{~A}$ similar behavior is observed for $\mathrm{Au}$ (Figure 8b): the $\mathrm{Q}_{\mathrm{abs}}$ values of $\alpha-\mathrm{Fe}_{2} \mathrm{O}_{3}$ present quite small values for $L>60 \mathrm{~nm}$, that is, when the LSPR wavelength is red-shifted beyond $660 \mathrm{~nm}$. For Al (Figure 8c), it is also observed that the $Q_{\mathrm{abs}}$ values for the $\alpha-\mathrm{Fe}_{2} \mathrm{O}_{3}$ component first increase with $L$ and then progressively decrease as $L$ is further increased to $L>40 \mathrm{~nm}$. On the basis of the results 
Table 1. LSPR Wavelength for HNs Composed of Metallic Counterparts of Different Nature and Lengths

\begin{tabular}{|c|c|c|c|}
\hline \multirow{2}{*}{$\frac{\text { metallic rod }}{\text { length, } L / \mathrm{nm}}$} & \multicolumn{3}{|c|}{ LSPR spectral position/nm } \\
\hline & $\alpha-\mathrm{Fe}_{2} \mathrm{O}_{3} / \mathrm{Ag}$ & $\alpha-\mathrm{Fe}_{2} \mathrm{O}_{3} / \mathrm{Au}$ & $\alpha-\mathrm{Fe}_{2} \mathrm{O}_{3} / \mathrm{Al}$ \\
\hline 10 & 420 & 520 & \\
\hline 20 & 438 & 540 & \\
\hline 30 & 461 & 560 & \\
\hline 40 & 500 & 580 & \\
\hline 50 & 550 & 600 & 400 \\
\hline 60 & 600 & 660 & 450 \\
\hline 70 & 640 & 680 & 480 \\
\hline 80 & 680 & 720 & 520 \\
\hline 90 & 720 & 750 & 560 \\
\hline 100 & 760 & 780 & 600 \\
\hline
\end{tabular}

presented above, it can be stated that, for a given metallic counterpart, the enhancement of $Q_{\mathrm{abs}}$ for the $\alpha-\mathrm{Fe}_{2} \mathrm{O}_{3}$ component is directly related to the tuning of the LSPR wavelength to the spectral region, where $\alpha-\mathrm{Fe}_{2} \mathrm{O}_{3}$ absorbs, that is, where $\operatorname{Im}\left(\varepsilon(\lambda)_{\alpha-\mathrm{Fe}_{2} \mathrm{O}_{3}}\right)>0$. However, this fact is unable to explain the substantial differences found in the $Q_{\mathrm{abs}}$ values according to the metallic counterpart of the HN. Thus, to be able to take out the most from the properties that allow HNs to convert light into chemical or electrical energy through a rational design of their structure, a more deep insight into the factors that control light harvesting is required.

Absorbed Photon Flux, $\phi$, within the $\alpha-\mathrm{Fe}_{2} \mathrm{O}_{3}$ Component. To evaluate the effectiveness of $\alpha-\mathrm{Fe}_{2} \mathrm{O}_{3} / \mathrm{M}$ rodlike $\mathrm{HNs}$ as light-harvesting devices, the absorbed photon flux, $\phi$, within the $\alpha-\mathrm{Fe}_{2} \mathrm{O}_{3}$ component has been calculated according to eq $2^{59}$

$$
\phi=\int_{\lambda=400 \mathrm{~nm}}^{\lambda=900 \mathrm{~nm}} I(\lambda) Q_{\mathrm{abs}}(\lambda) \mathrm{d} \lambda
$$

where the incident spectral photon flux, $I(\lambda)$, is given by $I(\lambda)=$ $\lambda I_{\mathrm{AM} 1.5 \mathrm{G}} / h c$, where $I_{\mathrm{AM} 1.5 \mathrm{G}}$ is the solar spectrum at AM1.5G conditions, $h$ is Planck's constant, and $c$ is the speed of light in vacuum. Figure 9a shows the dependence of $\phi$ on the length, $L$, of the metallic rods of the three different metals studied in this work. In all cases, it is observed that as $L$ increases from 10 to $100 \mathrm{~nm}, \phi$ increases up to a maximum value and then decreases. The rod length for which $\phi$ reaches the maximum value, $L_{\max }$ depends on the nature of the metallic rod, that is, $L_{\max }=45 \mathrm{~nm}$ for $\mathrm{Ag}$ and $\mathrm{Au}$ and $L_{\max }=60 \mathrm{~nm}$ for Al. In addition, it is clearly observed that the largest $\phi$ values are obtained using $\mathrm{Ag}$ or $\mathrm{Al}$ as the metallic counterpart of the $\mathrm{HN}$, whereas $\mathrm{Au}$ leads to smaller $\phi$ values. Indeed, the highest $\phi$ values for $\mathrm{Ag}$ and $\mathrm{Al}\left(\sim 11 \times 10^{16}\right.$ photons $\left.\mathrm{cm}^{-2} \mathrm{~s}^{-1}\right)$ are nearly 3 times larger than those corresponding to $\mathrm{HNs}$ composed of $\mathrm{Au}\left(\sim 4 \times 10^{16}\right.$ photons $\left.\mathrm{cm}^{-2} \mathrm{~s}^{-1}\right)$. This distinct behavior arises as a consequence of the different electric fields induced in the $\alpha-\mathrm{Fe}_{2} \mathrm{O}_{3}$ component by the metallic counterpart at each different wavelength.

Ingram et al. have shown that the spectral overlap among the illumination source spectrum, semiconductor absorbance spectrum, and metal nanoparticle LSPR spectrum provides a useful descriptor for predicting the LSPR-induced enhancement rate for the composite photocatalyst and guiding the formulation of optimal plasmonic metal/semiconductor photocatalysts. ${ }^{60}$ To establish a comparison with such experimental results and considering that the rate enhancement can be
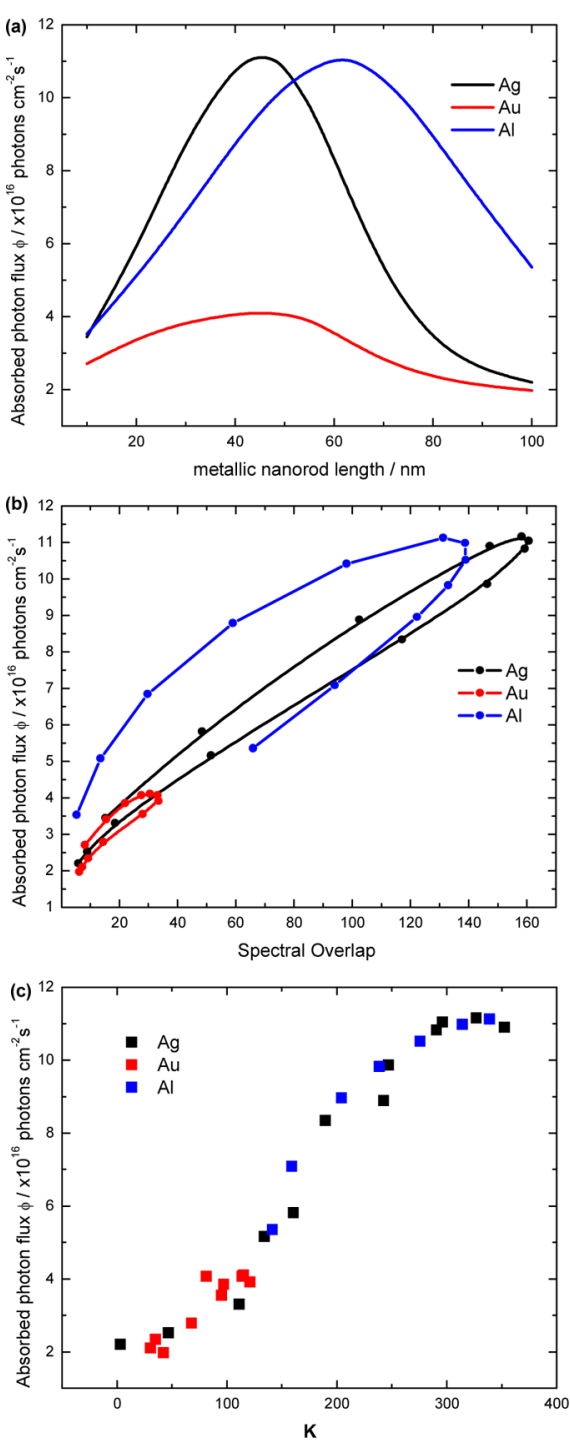

Figure 9. a) Dependence of the absorbed photon flux, $\phi$, within the $\alpha$ $\mathrm{Fe}_{2} \mathrm{O}_{3}$ component on the length, $L$, of the Ag (black curve), $\mathrm{Au}$ (red curve), and $\mathrm{Al}$ (blue curve) rods. (b) Dependence of the absorbed photon flux, $\phi$, within the $\alpha-\mathrm{Fe}_{2} \mathrm{O}_{3}$ component on the spectral overlap between the $Q_{\text {abs }}$ spectra of $\alpha-\mathrm{Fe}_{2} \mathrm{O}_{3}$ and Ag (black curve), Au (red curve), and $\mathrm{Al}$ (blue curve). (c) Dependence of the absorbed photon flux, $\phi$, within the $\alpha-\mathrm{Fe}_{2} \mathrm{O}_{3}$ component on parameter $\mathrm{K}$ for Ag (black dots), $\mathrm{Au}$ (red dots), and $\mathrm{Al}$ (blue dots), given by $K=I^{2} \Gamma_{\mathrm{R}} \mathrm{e}^{-E_{g} / E_{\text {res }}}$. The diameter of both components of the HNs as well as the length of the $\alpha-\mathrm{Fe}_{2} \mathrm{O}_{3}$ rod is $50 \mathrm{~nm}$ in all cases.

directly associated with the absorbed photon flux, $\phi$, Figure $9 \mathrm{~b}$ shows the $\phi$ values obtained through eq 2 plotted as a function of the spectral overlap for the three plasmonic metals studied in this work. At first glance, it can be observed that $\phi$ increases with the spectral overlap, in agreement with previous results. ${ }^{60}$ However, note that for any of the metals analyzed, the spectral overlap does not present one-to-one univocal correspondence with $\phi$. For instance, at a spectral overlap of 100, the curve for $\mathrm{Al}$ presents two quite different $\phi$ values, that is, 7.5 and $10.4 \times$ $10^{16}$ photons $\mathrm{cm}^{-2} \mathrm{~s}^{-1}$, respectively. This observation suggests that although the spectral overlap provides a useful descriptor for predicting the photoactive properties of $\mathrm{HNs}$ it has limitations to represent a definitive criterion able to discern about the largest absorbed photon flux between similar HNs. Moreover, the upper (lower) branch in each curve corresponds 

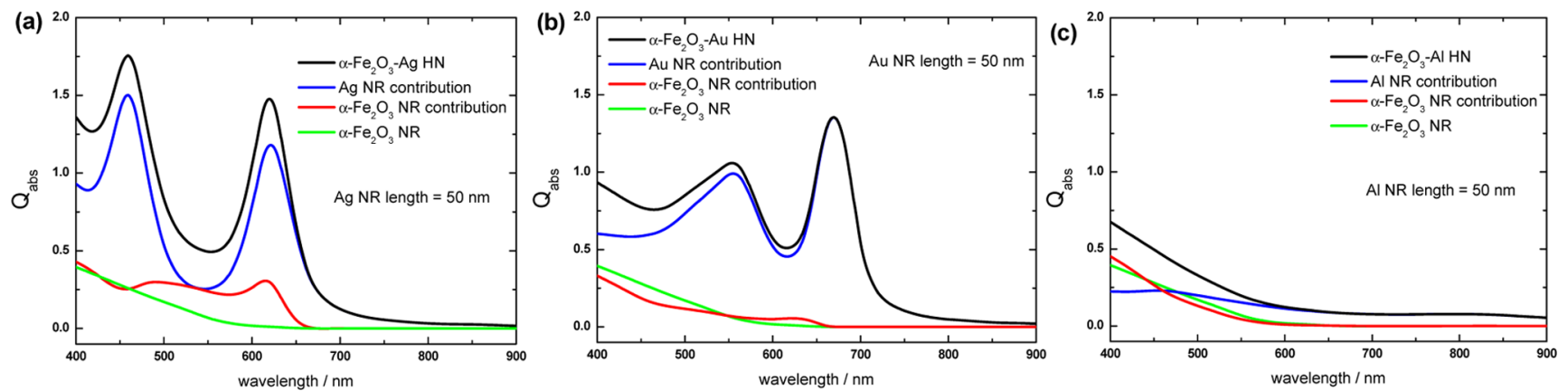

Figure 10. Absorption efficiency, $Q_{\mathrm{abs}}$, spectra of (a) $\alpha$ - $\mathrm{Fe}_{2} \mathrm{O}_{3} / \mathrm{Ag}$, (b) $\alpha-\mathrm{Fe}_{2} \mathrm{O}_{3} / \mathrm{Au}$, and (c) $\alpha$ - $\mathrm{Fe}_{2} \mathrm{O}_{3} / \mathrm{Al}$ HNs (black curves) excited with the incident electric field perpendicular to the major axis of the $\mathrm{HN}$. The red curves correspond to the respective contributions from the $\alpha$-Fe $\mathrm{O}_{3}$ component, whereas the blue curves correspond to the contribution from the respective plasmonic metal. The diameter and length of both components of the $\mathrm{HN}$ are $50 \mathrm{~nm}$ in all cases. For comparison, the $Q_{\text {abs }}$ spectrum of an isolated $\alpha-\mathrm{Fe}_{2} \mathrm{O}_{3}$ rod $(L=0 \mathrm{~nm})$ is also shown (green curve).

to NHs whose plasmonic component lengths are shorter (larger) than the $L_{\max }$. Thus, the experimental results shown in Figure $4 \mathrm{~b}$ of ref 60 can be associated with the upper branch of the curve that describes the dependence of $\phi$ on the spectral overlap (Figure 9b). The results presented here suggest that there is a need of a more quantitative figure of merit that allows the efficient design of photoactive HNs, that is, to determine the dimensions for a given $\mathrm{HN}$ composition that lead to the largest $\phi$ value. $\mathrm{Wu}$ and co-workers stated that PIRET can only occur when a spectral overlap is maintained, and PIRET can be better used to increase the absorption in a spectral region where the semiconductor absorbs weakly, such as near the band edge. ${ }^{38}$ Furthermore, these authors also argued that the relative dephasing times of the plasmon and semiconductor must be considered for efficient PIRET. On the basis of these arguments and considering that the dephasing time of the LSPR is linked to the LSPR line width, ${ }^{61}$ that the PIRET mechanism is more efficient for LSPR energies near the bandgap of the semiconductor material, and that the absorbed photon flux, $\phi$, should be proportional to the incident spectral photon flux, we have empirically found that parameter

$$
K=I^{2}\left(\lambda_{\text {LSPR }}\right) \Gamma_{\mathrm{R}} \mathrm{e}^{-E_{\mathrm{g}} / E_{\text {res }}}
$$

constitutes a quantitative figure of merit that allows us to guide the design of $\mathrm{HNs}$ toward those with enhanced photoactive properties. In eq $3, \Gamma_{R}$ stands for the nonradiative line width of the LSPR, $E_{\text {res }}$ corresponds to the LSPR energy, and $E_{\mathrm{g}}$ is the $\alpha$ $\mathrm{Fe}_{2} \mathrm{O}_{3}$ bandgap energy $(2.3 \mathrm{eV})$. Moreover, the incident spectral photon flux, $I$, in eq 3 is valuated at the resonance wavelength of the LSPR $\left(\lambda_{\mathrm{LSPR}}\right)$. Figure $9 \mathrm{c}$ shows the dependence of the absorbed photon flux, $\phi$, on parameter $K$ for the three different compositions of HNs studied in this work. The $E_{\text {res }}$ values for each metal and length $L$ were obtained from the respective $Q_{a b s}$ spectra, whereas the $\Gamma_{R}$ values were calculated according to the methodology described in ref 62 . Note that the values for each component on the right side of eq 3 corresponding to $\mathrm{Ag}, \mathrm{Au}$, and $\mathrm{Al}$ are provided in Tables $\mathrm{S} 1-$ S3, respectively. The data plotted in this way roughly lie in the same curve and evidence a direct proportionality between $\phi$ and $K$, indicating that the largest $\phi$ value is achieved for the largest $K$ value. The $K$ value can be interpreted as the result of the interplay among different quantities. Term $\mathrm{e}^{-E_{g} / E_{\text {res }}}$ accounts for the spectral overlap between the $Q_{a b s}$ spectra of the semiconductor and the metallic component of the HN. The relative amount of energy scattered into the environment produced after LSPR excitation capable of being absorbed by the nearby semiconductor material corresponds to a radiative loss, $\Gamma_{\mathrm{R}}$, that favors the absorbed flux of photons; therefore, it is introduced as a multiplicative factor in the expression of $K$. Finally, the inclusion of $I\left(\lambda_{\mathrm{LSPR}}\right)$ in the definition of parameter $K$ accounts for the dependence of the incident light intensity on the wavelength. Note that the relatively small variation of $\phi$ with $L$ near $L_{\max }$ (Figure 9a) provides a range where the length of the metallic component can be tuned without diminishing the $\phi$ value significantly with respect to the highest $\phi$ value, which constitutes an advantageous characteristic from the point of view of the preparation of this type of HNs. Furthermore, as it can be clearly seen in Figure 9a, the magnitude of this length range decreases in the order of $\mathrm{Au}, \mathrm{Al}$, and $\mathrm{Ag}$. This feature is also captured in Figure 9c, where for each metal, there exists a range of $K$ values for which $\phi$ exhibits small variations around the highest $\phi$ values. Thus, the results shown in Figure 9c indicate that the $K$ parameter constitutes a suitable predictor for guiding the design of photoactive HNs and for determining the optimum size according to a given specific metallic component.

Incident Electric Field Perpendicular to the Major Axis of the HN. All of the results presented and analyzed here were obtained with incident electric field $E_{0}$ parallel to the major axis of the HN. In this section, the effect of incident electric field perpendicular to the major axis of the $\mathrm{HN}$ on the absorption efficiency as well as on the $\phi$ values is analyzed to achieving a more complete picture. Figure 10 shows absorption efficiency, $Q_{\mathrm{abs}}$, spectra of (a) $\alpha-\mathrm{Fe}_{2} \mathrm{O}_{3} / \mathrm{Ag}$, (b) $\alpha-\mathrm{Fe}_{2} \mathrm{O}_{3} / \mathrm{Au}$, and (c) $\alpha$ $\mathrm{Fe}_{2} \mathrm{O}_{3} / \mathrm{Al} \mathrm{HNs}$ (black curves) excited with an incident electric field perpendicular to the major axis of the $\mathrm{HN}$. The red curves correspond to the respective contributions from the $\alpha-\mathrm{Fe}_{2} \mathrm{O}_{3}$ component, whereas the blue curves correspond to the contributions from the respective plasmonic metal. The diameter and length of both components of the $\mathrm{HN}$ are 50 $\mathrm{nm}$ in all cases. For comparison, the $Q_{\mathrm{abs}}$ spectrum of an isolated $\alpha-\mathrm{Fe}_{2} \mathrm{O}_{3}$ rod $(L=0 \mathrm{~nm})$ is also shown (green curve). The change in the orientation of the incident electric field from parallel to perpendicular with respect to the $\mathrm{HN}$ major axis produces substantial modifications in the main features of the $Q_{\text {abs }}$ spectra. Indeed, for the $\alpha-\mathrm{Fe}_{2} \mathrm{O}_{3} / \mathrm{Ag} \mathrm{HN}$, two absorption peaks can be clearly observed, which are almost exclusively due to the absorption of the plasmonic metal component, revealing notable differences with respect to the excitation with a parallel incident electric field where only one absorption peak is observed (see Figure 2a). These absorption peaks are attributed to multipole plasmonic excitations, and a detailed characterization of these transverse resonance modes is outside the 
scope of this work. Importantly, the most relevant finding is that the intensity of the $Q_{\mathrm{abs}}$ spectrum of the $\alpha-\mathrm{Fe}_{2} \mathrm{O}_{3}$ component is not significantly enhanced when it is coupled to the $\mathrm{Ag}$ rod (Figure 10a, red curve) in comparison to that of the $Q_{\mathrm{abs}}$ spectrum of the isolated $\alpha-\mathrm{Fe}_{2} \mathrm{O}_{3}$ rod (Figure 10a, green curve). Similar features are observed for the $\alpha-\mathrm{Fe}_{2} \mathrm{O}_{3} / \mathrm{Au}$ $\mathrm{HN}$, although in this case, the increase in the intensity of the $Q_{\text {abs }}$ spectrum of the $\alpha-\mathrm{Fe}_{2} \mathrm{O}_{3}$ component (Figure $10 \mathrm{~b}$, red curve) is much less pronounced than that corresponding to the isolated $\alpha-\mathrm{Fe}_{2} \mathrm{O}_{3}$ rod (Figure 10b, green curve). In the case of the $\alpha-\mathrm{Fe}_{2} \mathrm{O}_{3} / \mathrm{Al} \mathrm{HN}$, the $Q_{\text {abs }}$ spectrum of the $\mathrm{Al}$ component (Figure 10, blue curve) only presents a wide and very low intensity peak at around $500 \mathrm{~nm}$. Recall that the plasmon resonances of $\mathrm{Al}$ appear blue-shifted in comparison to those of $\mathrm{Ag}$ and $\mathrm{Au}$ because of its dielectric properties. On the other hand, the $Q_{\mathrm{abs}}$ spectrum of the $\alpha-\mathrm{Fe}_{2} \mathrm{O}_{3}$ component (Figure $10 c$, red curve) is quite similar to that corresponding to the isolated $\alpha-\mathrm{Fe}_{2} \mathrm{O}_{3}$ rod (Figure 10c, green curve); that is, the absorption properties of $\alpha-\mathrm{Fe}_{2} \mathrm{O}_{3}$ remain practically unaltered when it forms the $\mathrm{HN}$ and it is excited with the incident electric field perpendicular to the major axis of the $\mathrm{HN}$. Additional $Q_{\mathrm{abs}}$ spectra for $\alpha-\mathrm{Fe}_{2} \mathrm{O}_{3} / \mathrm{Ag}, \alpha-\mathrm{Fe}_{2} \mathrm{O}_{3} / \mathrm{Au}$, and $\alpha-\mathrm{Fe}_{2} \mathrm{O}_{3} / \mathrm{Al}$ with $L=$ 30 and $70 \mathrm{~nm}$ are provided in Figures S4-S6, respectively, which exhibit qualitatively the same features as those in the spectra presented in Figure 10. Therefore, the results obtained in general indicate that under excitation with the incident electric field perpendicular to the $\mathrm{HN}$ major axis $\mathrm{Ag}$ leads to moderate enhancements of the $Q_{\text {abs }}$ spectrum of the $\alpha-\mathrm{Fe}_{2} \mathrm{O}_{3}$ component in comparison to those of the $Q_{\mathrm{abs}}$ spectrum of the isolated $\alpha-\mathrm{Fe}_{2} \mathrm{O}_{3}$ rod, whereas $\mathrm{Au}$ and $\mathrm{Al}$ lead to rather negligible enhancements. Furthermore, the results obtained also show that excitation with the incident electric field parallel to the $\mathrm{HN}$ major axis produces larger enhancements in the $Q_{\mathrm{abs}}$ spectrum of the $\alpha-\mathrm{Fe}_{2} \mathrm{O}_{3}$ component in comparison to those under excitation with a perpendicular incident electric field. In fact, the absorbed photon flux, $\phi$, within the $\alpha-\mathrm{Fe}_{2} \mathrm{O}_{3}$ component for the $\alpha-\mathrm{Fe}_{2} \mathrm{O}_{3} / \mathrm{Ag}, \alpha-\mathrm{Fe}_{2} \mathrm{O}_{3} / \mathrm{Au}$, and $\alpha-\mathrm{Fe}_{2} \mathrm{O}_{3} /$ $\mathrm{Al} \mathrm{HNs,} \mathrm{whose} \mathrm{spectra} \mathrm{are} \mathrm{shown} \mathrm{in} \mathrm{Figure} \mathrm{10,} \mathrm{decreases} \mathrm{from}$ $1.08 \times 10^{17}, 4.07 \times 10^{16}$, and $1.04 \times 10^{17}$ photons $\mathrm{cm}^{-2} \mathrm{~s}^{-1}$ to $4.23 \times 10^{16}, 1.78 \times 10^{16}$, and $1.83 \times 10^{16}$ photons $\mathrm{cm}^{-2} \mathrm{~s}^{-1}$, respectively, when the incident electric field orientation is changed from parallel to perpendicular. The differences in the intensity of the $Q_{\mathrm{abs}}$ spectrum of the $\alpha-\mathrm{Fe}_{2} \mathrm{O}_{3}$ component and in the $\phi$ values according to the orientation of the incident electric field with respect to the $\mathrm{HN}$ major axis are attributed to the different near-field values generated by the excitation of longitudinal and transverse plasmon resonance modes, respectively.

\section{CONCLUSIONS}

In this work, we have theoretically studied the light-harvesting properties of hematite/plasmonic metal HNs by means of DDA simulations. The nanostructures investigated consist of a $\alpha$ $\mathrm{Fe}_{2} \mathrm{O}_{3}$ nanocylinder attached through its base to a nanocylinder composed of $\mathrm{Ag}, \mathrm{Au}$, or $\mathrm{Al}$, respectively. Both components have the same diameter $(50 \mathrm{~nm})$, whereas the length of the metallic component, $L$, was varied systematically in the $0-100 \mathrm{~nm}$ range. The strategy implemented in this work can be applied to study the far- and near-field optical properties of any other multicomponent $\mathrm{HN}$ with arbitrary geometry and allows us to obtain information not accessible through standard spectroscopic techniques. In addition, on the basis of the $Q_{\mathrm{abs}}$ data, it was possible to calculate the absorbed photon flux, $\phi$, for each size and composition of HNs. It was found that both the absorption efficiency, $Q_{\mathrm{abs}}$, and the absorbed photon flux, $\phi$, can be substantially enhanced through a proper selection of the nature and length of the metallic counterpart. Importantly, it was also found that the highest $\phi$ values for HNs composed of $\mathrm{Ag}$ and $\mathrm{Al}\left(\sim 11 \times 10^{16}\right.$ photons $\left.\mathrm{cm}^{-2} \mathrm{~s}^{-1}\right)$ are nearly 3 times larger than those corresponding to HNs composed of $\mathrm{Au}(\sim 4$ $\times 10^{16}$ photons $\left.\mathrm{cm}^{-2} \mathrm{~s}^{-1}\right)$. This evidence of plasmon-enhanced light absorption in the $\alpha-\mathrm{Fe}_{2} \mathrm{O}_{3}$ component is attributed to a plasmon-induced energy transfer mechanism based on nearfield enhancements. In addition, a direct relationship between the absorbed photon flux, $\phi$, and optical characteristics of the nanostructures, that is, the bandgap energy of $\alpha-\mathrm{Fe}_{2} \mathrm{O}_{3}, E_{\mathrm{g}}$, and the energy, $E_{\text {res }}$, and radiative line width, $\Gamma_{R}$ of the LSPR, was empirically obtained. Particularly, it was inferred that $\phi$ increases proportionally to a new figure of merit denoted $K$, explicitly given by the following expression: $K=I^{2} \Gamma_{\mathrm{R}} \mathrm{e}^{-E_{\mathrm{g}} / E_{\text {res }}}$. Such a relationship expresses the complex interplay that controls plasmon-enhanced light absorption processes, indicating that getting the largest $\phi$ requires not only the tuning of the spectral overlap through the term $\mathrm{e}^{-E_{\mathrm{g}} / E_{\text {res }}}$ but also taking into account the radiative decay of the plasmonic excitation. Consequently, the relationship between $\phi$ and $K$ provides advantageous criteria to guide the optimum design of hybrid nanostructures with enhanced photoactive properties. Importantly, this criterion not only complements but also goes beyond the limitations of previously reported useful criteria. We believe that the results presented in this work provide valuable information for achieving a more efficient design of HNs with applications in photovoltaic and/or photocatalytic processes.

\section{ASSOCIATED CONTENT}

\section{Supporting Information}

The Supporting Information is available free of charge on the ACS Publications website at DOI: 10.1021/acs.jpcc.7b12486.

Near-field patterns of $\alpha$ - $\mathrm{Fe}_{2} \mathrm{O}_{3} / \mathrm{Ag}, \alpha-\mathrm{Fe}_{2} \mathrm{O}_{3} / \mathrm{Au}$, and $\alpha$ $\mathrm{Fe}_{2} \mathrm{O}_{3} / \mathrm{Al} \mathrm{HNs}$ excited at their respective plasmon resonance wavelengths; absorption efficiency, $Q_{\mathrm{abs}}$, spectra of $\alpha$ - $\mathrm{Fe}_{2} \mathrm{O}_{3} / \mathrm{Ag}, \alpha-\mathrm{Fe}_{2} \mathrm{O}_{3} / \mathrm{Au}$, and $\alpha-\mathrm{Fe}_{2} \mathrm{O}_{3} / \mathrm{Al}$ $\mathrm{HNs}$ excited with the incident electric field perpendicular to the major axis of the $\mathrm{HN}$; and values of each component on the right side of eq 3 for $\alpha-\mathrm{Fe}_{2} \mathrm{O}_{3} / \mathrm{Ag}, \alpha$ $\mathrm{Fe}_{2} \mathrm{O}_{3} / \mathrm{Au}$, and $\alpha-\mathrm{Fe}_{2} \mathrm{O}_{3} / \mathrm{Al} \mathrm{HNs}$ (PDF)

\section{AUTHOR INFORMATION}

\section{Corresponding Authors}

*E-mail: ezencina@fcq.unc.edu.ar (E.R.E.).

*E-mail: coronado@fcq.unc.edu.ar. Tel: +54-351-535-3866. Fax: +54-351-433-4180 (E.A.C.).

\section{ORCID}

Ezequiel R. Encina: 0000-0001-5664-8541

Eduardo A. Coronado: 0000-0002-0748-6803

\section{Notes}

The authors declare no competing financial interest.

\section{ACKNOWLEDGMENTS}

The authors thank CONICET (PIP 112-201101-00430), FONCYT (PICT-2012-2286), and SECyT (UNC) for financial support. 


\section{REFERENCES}

(1) Liu, X.; Iocozzia, J.; Wang, Y.; Cui, X.; Chen, Y.; Zhao, S.; Li, Z.; Lin, Z. Noble Metal-Metal Oxide Nanohybrids with Tailored Nanostructures for Efficient Solar Energy Conversion, Photocatalysis and Environmental Remediation. Energy Environ. Sci. 2017, 10, 402434.

(2) Naldoni, A.; Riboni, F.; Guler, U.; Boltasseva, A.; Shalaev, V. M.; Kildishev, A. V. Solar-Powered Plasmon-Enhanced Heterogeneous Catalysis. Nanophotonics 2016, 5, 112-133.

(3) Zhou, N.; López-Puente, V.; Wang, Q.; Polavarapu, L.; PastorizaSantos, I.; Xu, Q.-H. Plasmon-Enhanced Light Harvesting: Applications in Enhanced Photocatalysis, Photodynamic Therapy and Photovoltaics. RSC Adv. 2015, 5, 29076-29097.

(4) Lou, Z.; Wang, Z.; Huang, B.; Dai, Y. Synthesis and Activity of Plasmonic Photocatalysts. Chem CatChem 2014, 6, 2456-2476.

(5) Linic, S.; Christopher, P.; Ingram, D. B. Plasmonic-Metal Nanostructures for Efficient Conversion of Solar to Chemical Energy. Nat. Mater. 2011, 10, 911-921.

(6) Ye, W.; Long, R.; Huanga, H.; Xiong, J. Plasmonic Nanostructures in Solar Energy Conversion. J. Mater. Chem. C 2017, $5,1008-1021$.

(7) Ueno, K.; Oshikiri, T.; Misawa, H. Plasmon-Induced Water Splitting Using Metallic-Nanoparticle-Loaded Photocatalysts and Photoelectrodes. ChemPhysChem 2016, 17, 199-215.

(8) Smith, J. G.; Faucheaux, J. A.; Jain, P. K. Plasmon Resonances for Solar Energy Harvesting: A Mechanistic Outlook. Nano Today 2015, $10,67-80$.

(9) Li, J.; Wu, N. Semiconductor-Based Photocatalysts and Photoelectrochemical Cells for Solar Fuel Generation: A Review. Catal. Sci. Technol. 2015, 5, 1360-1384.

(10) Iandolo, B.; Wickman, B.; Zorić, I.; Hellman, A. The Rise of Hematite: Origin and Strategies to Reduce the High Onset Potential for the Oxygen Evolution Reaction. J. Mater. Chem. A 2015, 3, 1689616912 .

(11) Li, B.; Hao, Y.; Shao, X.; Tang, H.; Wang, T.; Zhu, J.; Yan, S. Synthesis of Hierarchically Porous Metal Oxides and $\mathrm{Au} / \mathrm{TiO}_{2}$ Nanohybrids for Photodegradation of Organic Dye and Catalytic Reduction of 4-Nitrophenol. J. Catal. 2015, 329, 368-378.

(12) Amrollahi, R.; Hamdy, M. S.; Mul, G. Understanding Promotion of Photocatalytic Activity of $\mathrm{TiO}_{2}$ by Au Nanoparticles. J. Catal. 2014, 319, 194-199.

(13) Kochuveedu, S. T.; Jang, Y. H.; Kim, D. H. A Study on the Mechanism for the Interaction of Light with Noble Metal-Metal Oxide Semiconductor Nanostructures for Various Photophysical Applications. Chem. Soc. Rev. 2013, 42, 8467-8493.

(14) Zhang, L.; Mohamed, H. H.; Dillert, R.; Bahnemann, D. Kinetics and Mechanisms of Charge Transfer Processes in Photocatalytic Systems: A Review. J. Photochem. Photobiol., C 2012, 13, 263276.

(15) Thomann, I.; Pinaud, B. A.; Chen, Z.; Clemens, B. M.; Jaramillo, T. F.; Brongersma, M. L. Plasmon Enhanced Solar-to-Fuel Energy Conversion. Nano Lett. 2011, 11, 3440-3446.

(16) She, P.; Xu, K.; Zeng, S.; He, Q.; Sun, H.; Liu, Z. Investigating the Size Effect of $\mathrm{Au}$ Nanospheres on the Photocatalytic Activity of Au-modified $\mathrm{ZnO}$ nanorods. J. Colloid Interface Sci. 2017, 499, 76-82.

(17) Fan, W.; Leung, M. K. H. Recent Development of Plasmonic Resonance-Based Photocatalysis and Photovoltaics for Solar Utilization. Molecules 2016, 21, 180.

(18) Fang, C.; Jia, H.; Chang, S.; Ruan, Q.; Wang, P.; Chen, T.; Wang, J. (Gold Core)/(Titania Shell) Nanostructures for PlasmonEnhanced Photon Harvesting and Generation of Reactive Oxygen Species. Energy Environ. Sci. 2014, 7, 3431-3438.

(19) Yuzawa, H.; Yoshida, T.; Yoshida, H. Gold Nanoparticles on Titanium Oxide Effective for Photocatalytic Hydrogen Formation Under Visible Light. Appl. Catal., B 2012, 115-116, 294-302.

(20) Zhou, X.; Liu, G.; Yu, J.; Fan, W. Surface Plasmon ResonanceMediated Photocatalysis by Noble Metal-Based Composites Under Visible Light. J. Mater. Chem. 2012, 22, 21337-21354.
(21) Encina, E. R.; Passarelli, N.; Coronado, E. A. Plasmon Enhanced Light Absorption in Aluminium@Hematite Core Shell Hybrid Nanocylinders: the Critical Role of Length. RSC Adv. 2017, 7, 2857-2868.

(22) Koren, M. G.; Dotan, H.; Rothschild, A. Nano Gold Rush: On the Origin of the Photocurrent Enhancement in Hematite Photoanodes Decorated with Gold Nanoparticles. J. Phys. Chem. C 2016, 120, 15042-15051.

(23) Jia, C.; Li, X.; Xin, N.; Gong, Y.; Guan, J.; Meng, L.; Meng, S.; Guo, X. Interface-Engineered Plasmonics in Metal/Semiconductor Heterostructures. Adv. Energy Mater. 2016, 6, No. 1600431.

(24) Feng, W.; Wang, B.; Zheng, Z.; Fang, Z.; Wang, Z.; Zhang, S.; Li, Y.; Liu, P. Predictive Model for Optimizing the Near-Field Electromagnetic Energy Transfer in Plasmonic NanostructureInvolved Photocatalysts. Appl. Catal., B 2016, 186, 143-150.

(25) Khan, M. R.; Chuan, T. W.; Yousuf, A.; Chowdhury, M. N. K.; Cheng, C. K. Schottky Barrier and Surface Plasmonic Resonance Phenomena towards the Photocatalytic Reaction: Study of their Mechanisms to Enhance Photocatalytic Activity. Catal. Sci. Technol. 2015, 5, 2522-2531.

(26) Jiang, R.; Li, B.; Fang, C.; Wang, J. Metal/Semiconductor Hybrid Nanostructures for Plasmon-Enhanced Applications. Adv. Mater. 2014, 26, 5274-5309.

(27) Hou, W.; Cronin, S. B. A Review of Surface Plasmon Resonance-Enhanced Photocatalysis. Adv. Funct. Mater. 2013, 23, $1612-1619$.

(28) Liu, L.; Ouyang, S.; Ye, J. Gold-Nanorod-Photosensitized Titanium Dioxide with Wide-Range Visible-Light Harvesting Based on Localized Surface Plasmon Resonance. Angew. Chem., Int. Ed. 2013, 52, 6689-6693.

(29) Xiao, M.; Jiang, R.; Wang, F.; Fang, C.; Wang, J.; Yu, J. C. Plasmon-Enhanced Chemical Reactions. J. Mater. Chem. A 2013, 1, 5790.

(30) Wang, P.; Huang, B.; Dai, Y.; Whangbo, M.-H. Plasmonic Photocatalysts: Harvesting Visible Light with Noble Metal Nanoparticles. Phys. Chem. Chem. Phys. 2012, 14, 9813-9825.

(31) Carbone, L.; Cozzoli, P. D. Colloidal Heterostructured Nanocrystals: Synthesis and Growth Mechanisms. Nano Today 2010, 5, 449-493.

(32) Zhang, X.; Chen, Y. L.; Liu, R.-S.; Tsai, D. P. Plasmonic Photocatalysis. Rep. Prog. Phys. 2013, 76, No. 046401.

(33) Coronado, E. A.; Encina, E. R.; Stefani, F. D. Optical Properties of Metallic Nanoparticles: Manipulating Light, Heat and Forces at the Nanoscale. Nanoscale 2011, 3, 4042-4059.

(34) Kelly, K. L.; Coronado, E.; Zhao, L. L.; Schatz, G. C. The Optical Properties of Metal Nanoparticles: The Influence of Size, Shape, and Dielectric Environment. J. Phys. Chem. B 2003, 107, 668677.

(35) Cushing, S. K.; Wu, N. Progress and Perspectives of PlasmonEnhanced Solar Energy Conversion. J. Phys. Chem. Lett. 2016, 7, 666675.

(36) Ma, X.-C.; Dai, Y.; Yu, L.; Huang, B.-B. Energy Transfer in Plasmonic Photocatalytic Composites. Light: Sci. Appl. 2016, 5, No. e16017.

(37) Li, J.; Cushing, S. K.; Meng, F.; Senty, T. R.; Bristow, A. D.; Wu, N. Plasmon-Induced Resonance Energy Transfer for Solar Energy Conversion. Nat. Photonics 2015, 9, 601-608.

(38) Cushing, S. K.; Bristowa, A. D.; Wu, N. Theoretical Maximum Efficiency of Solar Energy Conversion in Plasmonic Metal-Semiconductor Heterojunctions. Phys. Chem. Chem. Phys. 2015, 17, 3001330022.

(39) Clavero, C. Plasmon-Induced Hot-Electron Generation at Nanoparticle/Metal-Oxide Interfaces for Photovoltaic and Photocatalytic Devices. Nat. Photonics 2014, 8, 95-103.

(40) Cornell, R. M.; Schwertmann, U. The Iron Oxides: Structure, Properties, Reactions, Occurrence and Uses; VCH: Weinheim, 2003.

(41) Shinde, P. S.; Lee, S. Y.; Ryu, J.; Choi, S. H.; Jang, J. S. Enhanced Photoelectrochemical Performance of Internally Porous Au-Embedded 
$\alpha-\mathrm{Fe}_{2} \mathrm{O}_{3}$ Photoanodes for Water Oxidation. Chem. Commun. 2017, 53, $4278-4281$.

(42) Verma, A.; Srivastav, A.; Khan, S. A.; Satsangi, V. R.; Shrivastav, R.; Avasthi, D. K.; Dass, S. Enhanced Photoelectrochemical Response of Plasmonic $\mathrm{Au}$ Embedded $\mathrm{BiVO}_{4} / \mathrm{Fe}_{2} \mathrm{O}_{3}$ Heterojunction. Phys. Chem. Chem. Phys. 2017, 19, 15039-15049.

(43) Banerjee, A.; Mondal, B.; Verma, A.; Satsangi, V. R; Shrivastav, R.; Dey, A.; Dass, S. Enhancing Efficiency of $\mathrm{Fe}_{2} \mathrm{O}_{3}$ for Robust and Proficient Solar Water Splitting Using a Highly Dispersed Bioinspired Catalyst. J. Catal. 2017, 352, 83-92.

(44) Zhang, P.; Wang, T.; Gong, J. Mechanistic Understanding of the Plasmonic Enhancement for Solar Water Splitting. Adv. Mater. 2015, $27,5328-5342$.

(45) Sivula, K.; Le Formal, F.; Grätzel, M. Solar Water Splitting: Progress Using Hematite $\left(\alpha-\mathrm{Fe}_{2} \mathrm{O}_{3}\right)$ Photoelectrodes. ChemSusChem 2011, 4, 432-449.

(46) Show, B.; Mukherjee, N.; Mondal, A. $\alpha$ - $\mathrm{Fe}_{2} \mathrm{O}_{3}$ Nanospheres: Facile Synthesis and Highly Efficient Photo-Degradation of Organic Dyes and Surface Activation by Nano-Pt for Enhanced Methanol Sensing. RSC Adv. 2016, 6, 75347-75358.

(47) Bai, L.; Li, F.; Wang, Y.; Li, H.; Jiang, X.; Sun, L. Visible-LightDriven Selective Oxidation of Benzyl Alcohol and Thioanisole by Molecular Ruthenium Catalyst Modified Hematite. Chem. Commun. 2016, 52, 9711-9714.

(48) Li, Y.; Zhao, J.; You, W.; Cheng, D.; Ni, W. Gold Nanorod@ Iron Oxide Core-Shell Heterostructures: Synthesis, Characterization, and Photocatalytic Performance. Nanoscale 2017, 9, 3925-3933.

(49) http://www.ddscat.org/.

(50) Purcell, E. M.; Pennypacker, C. R. Scattering and Absorption of Light by Nonspherical Dielectric Grains. Astrophys. J. 1973, 186, 705714.

(51) Draine, B. T. The Discrete-Dipole Approximation and its Application to Interstellar Graphite Grains. Astrophys. J. 1988, 333, 848-872.

(52) Draine, B. T.; Flatau, P. J. Discrete Dipole Approximation for Scattering Calculations. J. Opt. Soc. Am. A 1994, 11, 1491-1499.

(53) Flatau, P. J.; Draine, B. T. Fast Near-Field Calculations in the Discrete Dipole Approximation for Regular Rectilinear Grids. Opt. Express 2012, 20, 1247-1252.

(54) Baffou, G.; Quidant, R.; Girard, C. Heat Generation in Plasmonic Nanostructures: Influence of Morphology. Appl. Phys. Lett. 2009, 94, No. 153109.

(55) Ryde, N. P.; Matijević, E. Color Effects of Uniform Colloidal Particles of Different Morphologies Packed Into Films. Appl. Opt. 1994, 33, 7275-7281.

(56) Rakić, A. D.; Djurišic, A. B.; Elazar, J. M.; Majewski, M. L. Optical Properties of Metallic Films for Vertical-Cavity Optoelectronic Devices. Appl. Opt. 1998, 37, 5271-5283.

(57) Palik, E. D. Handbook of Optical Constant of Solids; Academic Press: New York, 1985.

(58) Encina, E. R.; Coronado, E. A. Resonance Conditions for Multipole Plasmon Excitations in Noble Metal Nanorods. J. Phys. Chem. C 2007, 111, 16796-16801.

(59) Murphy, A. B.; Barnes, P. R. F.; Randeniya, L. K.; Plumb, I. C.; Grey, I. E.; Horne, M. D.; Glasscock, J. A. Efficiency of Solar Water Splitting Using Semiconductor Electrodes. Int. J. Hydrogen Energy 2006, 31, 1999-2017.

(60) Ingram, D. B.; Christopher, P.; Bauer, J. L.; Linic, S. Predictive Model for the Design of Plasmonic Metal/Semiconductor Composite Photocatalysts. ACS Catal. 2011, 1, 1441-1447.

(61) Sönnichsen, C.; Franzl, T.; Wilk, T.; von Plessen, G.; Feldmann, J.; Wilson, O.; Mulvaney, P. Drastic Reduction of Plasmon Damping in Gold Nanorods. Phys. Rev. Lett. 2002, 88, No. 077402.

(62) Ross, M. B.; Schatz, G. C. Radiative Effects in Plasmonic Aluminum and Silver Nanospheres and Nanorods. J. Phys. D: Appl. Phys. 2015, 48, No. 184004. 